\title{
An Analysis of Pakistan's National Curriculum of Mathematics at Secondary Level
}

\author{
Amjad Ali Rind ${ }^{1 *}$, and Shahid Hussain Mughal ${ }^{1}$ \\ ${ }^{1}$ Department of Education, Sukkur IBA University, Sukkur, Pakistan \\ * Corresponding Author:amjad.mphil18@iba-suk.edu.pk | Phone Number: +92-3073701390
}

(Received 17 August 2020; Accepted 24 August 2020)

\begin{abstract}
The purpose of the study were to analyze the curriculum document of National Curriculum of Mathematics of secondary grades. The study employed qualitative research paradigm within it the discourse analysis technique was used to analyze the mathematics curriculum document. Discourse analysis helps in understanding the written, spoken and signs language used in any document analysis. The sample of the study were foreword, introduction, objectives, reviewer's notes and list of reviewers, the sections of mathematics in the national curriculum of mathematics (2006) for secondary grades. The findings of the study revealed that the National Curriculum of mathematics (NCM) 2006 was focused on transfer of Knowledge. However, it neglected the conceptual understanding of essential subject matter. It has been also discovered that the content of the mathematics is not taught according to the prescribed curriculum. Moreover, standard were not implemented properly. The role learners were recipient of knowledge and that of teachers is transmitter. Thus, it neglected the participatory and constructive approach of teaching and learning mathematics. Moreover, the curriculum ideology was not considered while developing the mathematics curriculum. It is suggested that the curriculum developers should revisit the policy on social constructive approach so that curriculum can be taught conceptually rather than standard based. Moreover, formative assessment should be included throughout the year rather taking annual examinations. It is recommended that teachers should impart mathematics education by linking math to social context and encourage students to construct meanings socially.
\end{abstract}

Key Words: Curriculum Ideology; National Curriculum of Mathematics; Secondary education; Pakistan

\section{INTRODUCTION}

The curriculum is a document that includes an overall program of education including experiences whichever individual learners have in school. The purpose of the curriculum is to provide a roadmap with clear goals and specific objectives. These things are planned according to a framework or research which present a professional practice (Kelly, 2009). Mathematics is an important subject at all levels of education. It is being taught from class one up to university level. In Pakistan, the curriculum of mathematics is designed at the national level (Government of Pakistan, 2006). Moreover, more importance has been given to elementary and secondary mathematics because these are the foundations for the future success of students. It is considered the mother of all sciences because mathematics is involved in every field. Generally, Mathematics is not liked by Pakistani students due to its rough, dry and hard nature (Aijaz, 2001). Students feel much difficulty in learning mathematics. The students in Public sector schools in Pakistan are unable to solve two-digit addition and subtraction. Only $48 \%$ of students can solve the basic arithmetic problem (Dubash, 2018; Pakistan, 2015). The curriculum of mathematics subject comprises of conceptual understanding which not only requires analytical but also involves logical thinking. The student's efforts play a vital role in the learning of mathematics (Ellis, 2011). However, the teachers of public and private schools failed to impart analytical skills among students due to lack of knowledge about curriculum (Gulzar, \& Mahmood, 2019).

The documents of the National Curriculum of Mathematics 2006 is standard-based which means it is based on the social efficacy ideology. Social efficacy ideology focuses on the skills and specific abilities of an individual. This ideology advocate for performance-based education because it believes that human life is based on the principle of performing specific abilities. Thus, Education should prepare students for specific abilities and skills (Harb \& Thomure, 2020; Schiro, 1978). In the modern era, the curriculum based on the social construction ideology will improve the students learning outcomes because whenever students are allowed to construct their meaning of the world around them their understanding improves. Social construction ideology believes that knowledge, skills and intelligence can be utilized to solve the problems for the betterment of society (Kumar, 2019). Therefore, the study aimed to analyze the National Curriculum of Mathematics (NCM) which has been implemented from 2006-2007 educational year at the secondary level to find the gaps 
in the ideology and suggest a way forward for policymakers and curriculum developers. Also, this study aims at exploring the mathematics curriculum goals, teaching strategies, assessment and evaluation dimension of Curriculum.

The purpose of the current study is to critically analyze Pakistan's national curriculum document of mathematics for secondary grades. Mathematics is a core subject that has been taught from primary to secondary level in Pakistan. Mathematics is considered as one of the imported subjects and it has been emphasized in the national education policies of Pakistan. It enables learners to solve real-life problems. Mathematics also stimulates the cognitive functions of the brain and increases the thinking ability of the learners. It also enhances the rational thinking of students. Moreover, Mathematics skills have become necessary for meeting the demands of fast-forwarding technological society. The progress in STEM (Science, technology, engineering and Mathematics) is only possible by improving the mathematical skills of learners. Thus, the Government of Pakistan has introduced a standard based national curriculum for mathematics to meet the needs of a technologically advanced society. However, when it comes to implementation, Pakistan has a long history of not properly implementing education policies. The main concerns of this study are to find out the gaps in the curriculum through in-depth analysis. After reviewing the curriculum document of the national curriculum of mathematics (NCM) 2006, the researcher has found major gaps in the curriculum. First of all, the curriculum was designed on the inappropriate curriculum ideology. Secondly, it was more focused on skills rather than the understanding of the basic concepts. Thirdly, the curriculum document has not given a road map for the implementation of reasoning and justifying skills. So, these skills are missing in NCM 2006. Furthermore, although proper teaching strategies was given in the curriculum, yet proper instructions were missing in the National Curriculum of Mathematics 2006 for secondary grades. Therefore, this study is an attempt to explore the gaps and missing linking of teaching and learning of mathematics at the secondary level.

In education, the change is considered as part of intention and implementation of teaching and learning skills within a developed system. Change in the curriculum occurs due to difference in intended goals of learning and the implemented aspects of curriculum. Various researchers have studied the innovation in mathematics curriculum in different contexts (Clarke; 1997; Memon ,1997; Anderson \& Piazza ,1996;Mumme \& Weissglass ,1991 ) cited by (Khan, Farooqi, \& Mehmood, 2018) In the context of Pakistan, there are various factors that need to be considered for curriculum change and innovation in mathematics because it depends upon the interests and controversies existing in the development of education system within a country. The purpose of changing curriculum is to align it with national ideology, goals and developing a framework which may reduce the risk of failure while implementing the academic framework (Khan, Farooqi, $\&$ Mehmood, 2018). The national curriculum of mathematics in Pakistan consists of five standards .The standards were developed by keeping the competencies of teachers and students in mind as per the broader and flexible framework of education. In Pakistan, students mathematics achievement is measured through these five standards set for secondary level students. The five mathematics standards are: 1) Numbers and operations 2) Algebra 3) Measurement and geometry 4) Information handling 5) reasoning and logical thinking (Gulzar, 2019; Government of Pakistan, 2006).

Literature has suggested four ideologies of curriculum namely Scholar academy ideology, Social efficiency ideology, learner-centered ideology and Social reconstruction ideology (Alazani, 2016; Apple, 2004). The researcher has chosen the social construction ideology (lens) for the analysis of the Mathematics curriculum because this ideology advocates that curriculum should be designed according to the social perspective. This ideology assumes that society is unhealthy and the survival of society is threatened, the traditional mechanisms which are developed by society to deal with the social problems are incapable of performing their jobs. Social reconstruction ideology assumes that society must be reconstructed so that the destruction of society can be prevented. In the social perspective, ideology education should be mean to solve the problems faced by society, to provide awareness through education, in-depth understanding of the problems of society. Besides, through education, society can develop a world based on the vision of social justice (Cotti \& Schiro, 2004). This ideology enhances the use of intelligence knowledge and skills so that social problems can be resolved ( Schiro, 2008).

\section{RESEARCH METHOD}

The qualitative approach is used within it a document review was conducted in this study. The data were analyzed through a discourse analysis approach because it helps in understanding the written, spoken and sign language of any document. Discourse analysis is used by many social science researchers to review curriculum documents (Johnstone, 2017). Therefore, this methodology is suitable to determine the curriculum ideology of the National curriculum of mathematics 2006 for secondary classes (9th \& 10th). The education purposes that has been investigated by the researcher including the nature of the student, how the learning takes place, what is the role of teacher, what is the most indispensable knowledge and its nature that the curriculum should be concerned with and what should be the nature of assessment. The sample of this study is the foreword, introduction, objectives, reviewer's notes and list of reviewers, the sections of mathematics in the national curriculum 2006 with special emphasis on the syllabus of mathematics for secondary education.

\section{RESULTS AND DISCUSSION}

\subsection{Critical Analysis of National Curriculum of Mathematics}

Firstly, the NCM 2006 is developed based on Academic standards but the holistic development of students is ignored and they are not provided with the opportunity to construct meaning, think critically and logically. Secondly, this curriculum has neglected the instructional process according to the three domains of learning i.e. cognitive, affective and psychomotor. Thirdly, the role of the learner is passive in learning mathematics. Moreover, teachers are the transmitter of knowledge rather than enabling students to construct their meaning. Also, this curriculum is of more mechanical, however, a humanistic approach is missing. While students as social beings and construct meaning socially. 


\subsection{Analysis of content area of Mathematics Curriculum}

The National Curriculum of mathematics (NCM) 2006 is based on the five standards including numbers and operation, algebra, measurement and geometry, information handling and reasoning and logical thinking. However, the learners must be provided with a conceptual understanding of essential mathematical skills. In addition, reasoning and logical thinking skills must be promoted in the curriculum at all levels along with some integration of all the standards. It has been revealed through document review that the content of the mathematics is not taught according to the prescribed curriculum. Moreover, the three standards have been implemented to some extent but the important two standards i.e information handling and logical and reasoning are missing at the secondary level. Teachers used to deliver content in the traditional way because they are not aware of the curriculum of mathematics. Besides, the constructivist approach is not implemented in the secondary mathematics curriculum. Hence, the students, content and strategies were implemented in the context of the classroom. This is because the ideology of curriculum development was not considered while developing the mathematics curriculum.

\subsection{Gaps in National Curriculum of Mathematics 2006}

In the National Curriculum of Mathematics 2006, the social efficacy ideology is used in mathematics curriculum which is not appropriate because it focuses on the performance of skills and abilities. In social efficacy ideology, students neither construct meanings nor solve problems. Therefore, social construct ideology was used in the analysis of curriculum which advocates that learners should use their knowledge, intelligence and skills to solve the problems of society. This is the major gap in the ideology of mathematics curriculum 2006 which needs to be changed

The current curriculum is a standard based which focus on skills. However, it has neglected the humanistic perspective. Thus, the NMC 2006 should be redesigned according to the reconstruction ideology. Although there is mention of enhancement of critical skills of the student in the curriculum document. However, its implementation is missing at classroom level because teachers are not allowing students to create knowledge by themselves rather the focus is on content delivery and skill improvement.

The mathematics curriculum document 2006 emphasizes skills rather than understanding basic mathematic concepts, content is delivered through the standard-based program. However, the implementation of reasoning and justifying skills is missing at schools. The instructional process focuses on the procedural fluency and strategic competency but proper instruction process is missing in the NC 2006 and teaching strategies are mentioned but are not implemented in a proper way. In both ideologies students have a central role .however, social construction ideology gives more importance to the learner.NC 2006 talks about the construction of knowledge but in actual it never happens in actual classroom settings. The assessment process is based on yearlong because the summative assessment is more focused while formative assessment is neglected and only students memory is tested not the knowledge.

\subsection{Reorienting the Curriculum of Mathematics}

The new approach should be used while developing curriculum because in this era the students need to be more creative, analytical and critical to solve the complex issues of the world. Moreover, the children should be taught to adopt according to the new situations. Students should learn effectively by using cognitive skills. They must develop ability to solve the complex problems of society through constructing their knowledge. There is need to develop more effective and efficient classrooms for students so that teachers can teach them by using modern gadgets. Teachers can teach by putting students in real life situation. In this approach, students should be allowed to make the meaning of the world they live by using mathematics. A mechanism should be designed to implement the curriculum as it is designed and teaching strategies should be implemented because in NCM curriculum it was missing. The instruction process and activities should be designed as per constructivist approach .Moreover, assessment strategies could be changed to shorter period of time so that students can absorb the knowledge.

\section{CONCLUSION}

To conclude, mathematical and reasoning skills improve understanding of the world. Therefore, the content of mathematics should be regularly updated so that it should align with the goals and objectives set in the Nation curriculum. Moreover, the need to participate with students during math class to enhance teaching instructions. Examinations should be taken twice or thrice in a year from specific chapters for assigning grades. Assessment should be integrated according to the requirements of the mathematics subject. The curriculum should be designed and implemented by the schools under the benchmarks set by the Education department. Education with knowledge and skills should be provided to students so that they live their life confidently and successfully. To conclude, the curriculum is a guiding document which must be updated according to the needs of society. There should be a mechanism of constant feedback so that curriculum could meet the challenges of the new era. It is suggested that the curriculum developers should revisit the policy on social constructive approach so that curriculum can be taught conceptually rather than standard based. Moreover, formative assessment should be included throughout the year rather taking annual examinations. It is recommended that teachers should impart mathematics education by linking math to social context and encourage students to socially construct meaning of the world. 


\section{REFERENCES}

Aijaz, S. (2001). Learning achievement in primary schools of Pakistan: A quest for quality education: UNESCO.

Alanazi, S. (2016). Comparison for curriculum ideologies. American Research Journal of Humanities and Social Sciences, 2(1), 1-10.

Apple, M. W. (2004). Ideology and curriculum: Routledge.

Dubash, C. J. (2018). Improving 'Quality'in Education: is Spending Effectively Better than Spending More? European Journal of Multidisciplinary Studies, 7(1), 167-171.

Ellis, A. B. (2011). Generalizing-promoting actions: How classroom collaborations can support students' mathematical generalizations. Journal for Research in Mathematics Education, 42(4), 308-345.

Government of Pakistan. (2009). National education policy. Ministry of Education. Islamabad: Ministry of Education

Government of Pakistan. (2006). National education policy. Ministry of Education. Islamabad: Ministry of Education

Gulzar, K. (2019). Examining Grades as Valid Measures of Secondary School Students' Competence in Mathematics (Doctoral dissertation, University of the Punjab, Lahore).

Gulzar, K., \& Mahmood, N. (2019). Challenges to Maintaining Alignment between Secondary Level Mathematics Curriculum and Assessments in Pakistan. Journal of Research \& Reflections in Education (JRRE), 13(2).

Harb, M., \& Thomure, H. T. (2020). Connecting literacy to curriculum ideologies. Curriculum Perspectives, 1-7.

Haider, G. (2016). Process of Curriculum Development in Pakistan. International Journal of New Trends in Arts, Sports \& Science Education (IJTASE), 5(2).

Johnstone, B. (2017). Discourse analysis. John Wiley \& Sons.

Khan, H. M. A., Farooqi, M. T. K., \& Mehmood, S. (2018). Curriculum of Mathematics in Pakistan and International Standards: A Comparative Study. Global Social Sciences Review, 3(2), 275-302.

Kelly, A. V. (2009). The curriculum: Theory and practice: Sage.

Kumar, A. (2019). Curriculum studies in South Africa: Colonialism, constructivism, and outcomes-based education. In Curriculum in international contexts (pp. 21-48). Palgrave Macmillan, Cham.

Mahmood, K. (2010). Textbook evaluation in Pakistan: Issue of conformity to the national curriculum guidelines. Bulletin of Education and Research, 32(1).

Mahmood, M., \& Aziz, S. (2018). Curriculum development process at secondary level: Analysis of existing situation in Pakistan and proposing a model. Journal of Research in Social Sciences, 6(2), 64-82.

Pakistan, A. (2015). Annual Status of Education Report: ASER Pakistan 2015 National (Urban). Paper presented at the Lahore, Pakistan: South Asian Forum for Education Development.

Remillard, J., \& Kim, O. K. (2017). Knowledge of curriculum embedded mathematics: Exploring a critical domain of teaching. Educational Studies in Mathematics, 96(1), 65-81.

Yoon, S., Lee, A., \& Kwon, O. N. (2019). Analysis on the relationship between core competencies and mathematical competencies and the tasks for mathematical competencies: A case of high school'Mathematics' textbooks according to 2015 revised mathematics curriculum. The Mathematical Education, 58(1), 55-77. 